LA-UR- $9 \%=5144$

MEASUREMENTS OF SLANT AND VERTICAL TEC USING DATA

Title: FROM FORTE AND THE TRACKER RAY-TRACING CODE

RECEIVED

Author(s):

R. S. Massey

APR 061998

Submitted to:

Informal Distribution

OSTI

19980423162

Los Alamos

NATIONAL LABORATORY

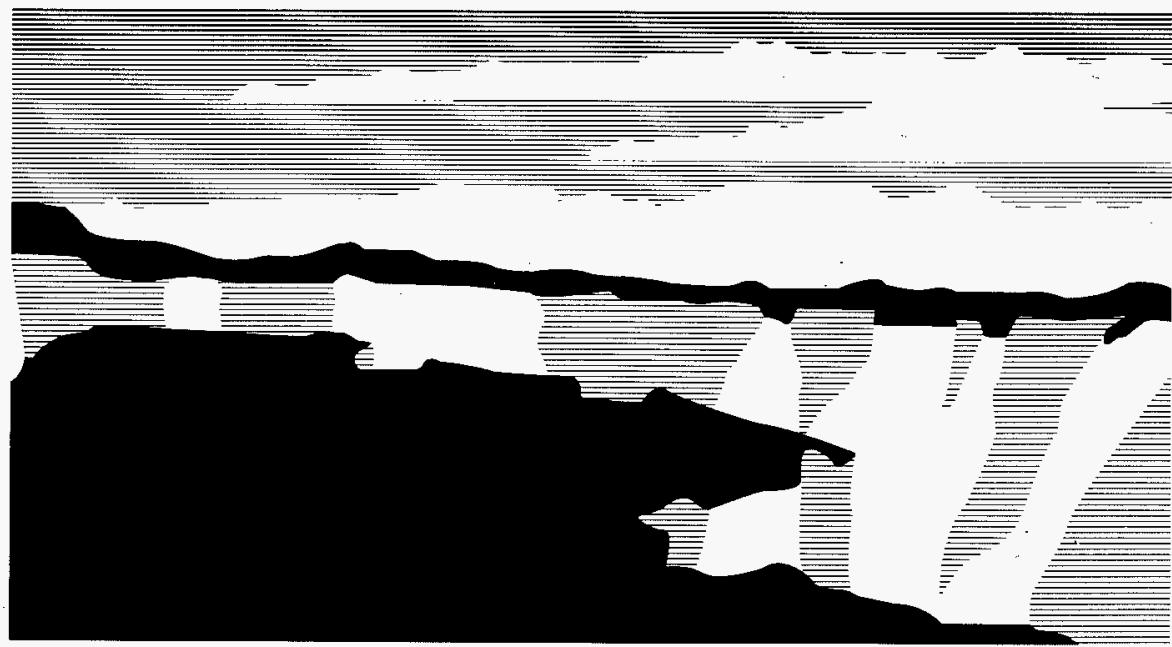

Los Alamos National Laboratory, an affirmative action/equal opportunity employer, is operated by the University of California for the U.S. Department of Energy under contract W-7405-ENG-36. By acceptance of this article, the publisher recognizes that the U.S. Government retains a nonexclusive, royalty-free license to publish or reproduce the published form of this contribution, or to allow others to do so, for U.S. Government purposes. The Los Alamos National Laboratory requests that the publisher identify this article as work performed under the auspices of the U.S. Department of Energy. 


\section{DISCLAIMER}

This report was prepared as an account of work sponsored by an agency of the United States Government. Neither the United States Government nor any agency thereof, nor any of their employees, makes any warranty, express or implied, or assumes any legal liability or responsibility for the accuracy, completeness, or usefulness of any information, apparatus, product, or process disclosed, or represents that its use would not infringe privately owned rights. Reference herein to any specific commercial product, process, or service by trade name, trademark, manufacturer, or otherwise does not necessarily constitute or imply its endorsement, recommendation, or favoring by the United States Government or any agency thereof. The views and opinions of authors expressed herein do not necessarily state or reflect those of the United States Government or any agency thereof. 


\title{
Measurements of slant and vertical TEC using data from FORTE and the TRACKER ray-tracing code.
}

\author{
R. S. Massey
}

\section{Introduction.}

In a previous informal report, I described the FORTE satellite and the analysis techniques used to extract a slant TEC from measurements of the dispersion of a signal transmitted from and EMP generator at Los Alamos. In this report I will report on the use of a ray-tracing/ionospheric model code to deduce the vertical TEC to $800 \mathrm{~km}$ from the FORTE measurements.

\section{Techniques.}

On several occasions we have transmitted impulses from a transmitter at $\operatorname{Los}$ Alamos, $N M\left(35.87^{\circ} \mathrm{N}\right.$, $-106.3^{\circ} \mathrm{E}$ ) to the FORTE satellite. There are about 6 impulses transmitted during each pass, and the elevation angle of course varies from shot to shot. In order to infer a vertical TEC, we need an appropriate ionospheric model. In this report, I use the TRACKER code, written by a team led by Paul Argo at LANL. TRACKER is a 3D ray-tracing code that incorporates the ICED ionospheric model. TRACKER was originally written for HF ray-tracing, but it has been modified and extensively tested for use in transionospheric ray-tracing. It has been benchmarked against another very different propagation code, called ITF (for Ionospheric Transfer Function), written by Bob Roussel-Dupré, also at LANL.

I ran TRACKER in a mode where it computed the group delays at the same set of frequencies received by FORTE, and compared the pseudo-TEC produced by TRACKER and by the FORTE data. By "pseudoTEC", I mean the coefficient $\mathrm{N}_{\mathrm{e}}$ of the $1 / \mathrm{f}^{2}$ fit to the group delay:

$$
\mathrm{t}_{\mathrm{i}}=\mathrm{t}_{0}+\frac{\mathrm{kN}_{\mathrm{e}}}{\mathrm{f}_{\mathrm{i}}^{2}}
$$

$\mathrm{N}_{\mathrm{e}}$ is a good approximation to the line integral of the electron density only when the frequency is very high, and we did not use frequencies above $85 \mathrm{MHz}$ in this report. Most of the data were taken in the 28$48 \mathrm{MHz}$ band, where higher-order terms are important. The residual errors between the TRACKER output and the $1 / \mathrm{f}^{2}$ fit are shown in figure 1 .The fit to equation 1 is (deceptively) good, because the higher-order terms are rather well correlated to $1 / \mathrm{f}^{2}$ in this frequency range. The pseudo-TEC nevertheless provides a convenient way to compare the measurements with results from the ray-tracing code. 

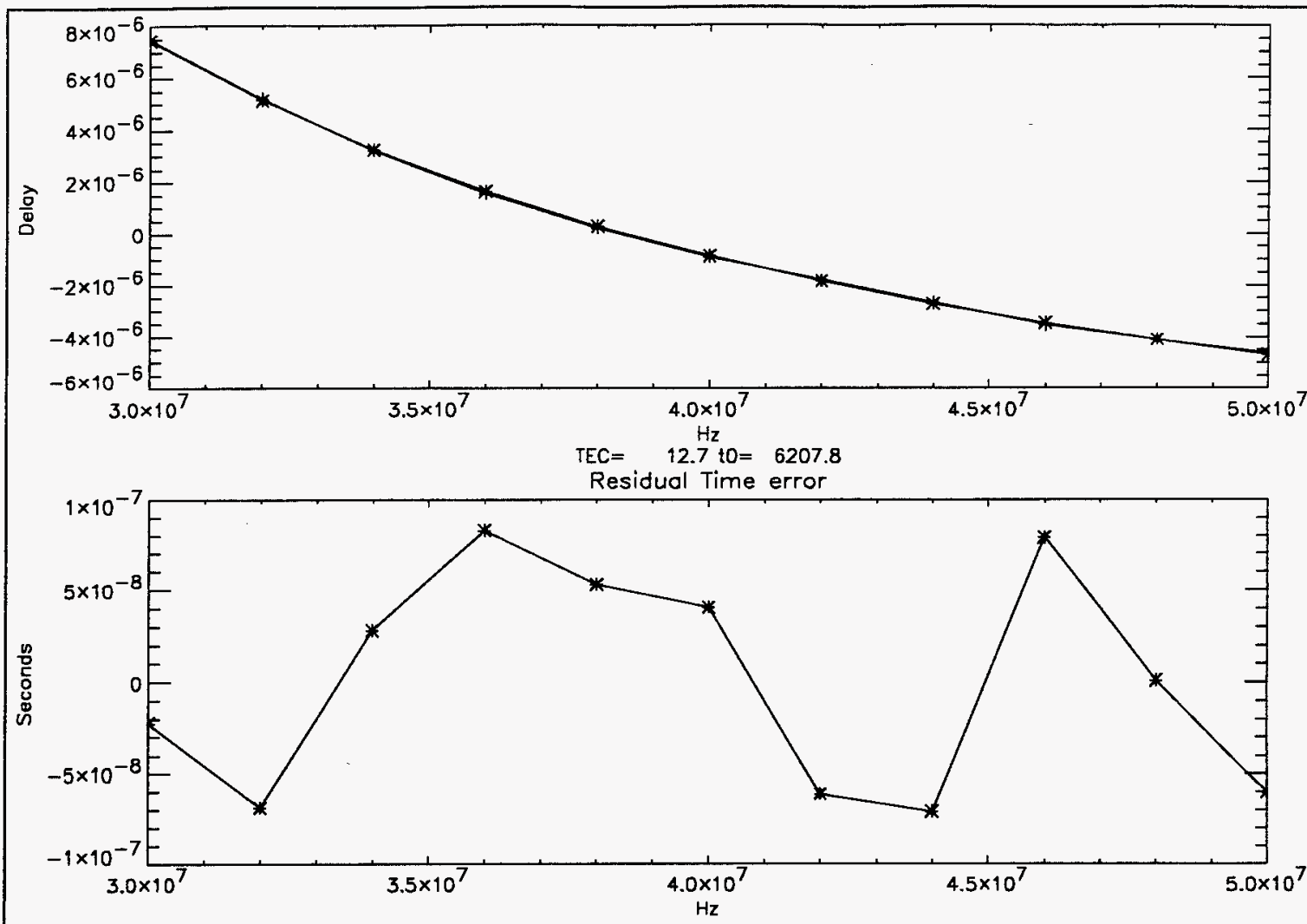

Figure 1. Top: plot of the group delay versus frequency for the TRACKER outputs (asterisks) and the $1 / f^{2}$ model. The group delay is in seconds, and the frequency is Hz. Bottom: the difference, in seconds, between the TRACKER results and the fit versus frequency in $\mathrm{Hz}$.

I varied the sunspot number used by ICED until I got reasonable agreement between the computed and measured pseudo-TEC at the highest elevation angle, and then input the other satellite positions with the same sunspot number to see how well the pseudo-TECs agreed at lower elevation angles.

Finally, to obtain the actual vertical TEC, I had TRACKER output the electron density profile above the transmitter, and integrated it to $800 \mathrm{~km}$.

\section{Results.}

We have had only 3 passes with elevation angles above $60^{\circ}$ since we began taking LAPP data with the main FORTE antenna deployed, and the receivers set up to do these measurements. The passes occurred on October 31, November 5 , and November 18, 1997. I will discuss the data from those passes in chronological order.

\section{October 31 data.}

The data from October 31 are summarized in table 1. Both FORTE TATR receivers were tuned to the 28$48 \mathrm{MHz}$ band, and the "coherent" technique described in my previous note was used to estimate the slant pseudo-TEC. 


\begin{tabular}{|r|r|r|r|r|r|r|r|r|}
\hline UT & AZ & EL & LAT & LON & ALT & TEC A & TEC B & TRACKER \\
\hline $14: 39: 00$ & 283.7 & 59.9 & 36.7 & -110.8 & 808636 & 13.7 & 11.8 & 12.7 \\
\hline $14: 40: 00$ & 332.7 & 54.1 & 39.9 & -109.0 & 808810 & 12.4 & 11.8 & 12.7 \\
\hline $14: 41: 00$ & 355.4 & 39.8 & 43.1 & -107.1 & 809021 & 15.5 & 15.0 & 15.2 \\
\hline $14: 42: 00$ & 5.3 & 28.1 & 46.2 & -105.0 & 809284 & 17.5 & 17.5 & 18.8 \\
\hline $14: 43: 00$ & 10.6 & 19.6 & 49.3 & -102.5 & 809611 & 22.5 & 23.6 & 23.6 \\
\hline $14: 44: 00$ & 13.9 & 13.1 & 52.3 & -99.7 & 809978 & 30.6 & & 28.8 \\
\hline
\end{tabular}

Table 1. Data from October 31 pass.

The columns, in order, are the Universal Time that the transmitter fired the pulse, the azimuth from north and elevation, in degrees, to the satellite, the latitude, east longitude (in degrees), and altitude (m) of the satellite, the pseudo-TEC for the A and B receivers, and the pseudo-TEC computed by TRACKER. The sunspot number used was 39 for all points. Both of the FORTE receivers were tuned to the $28-48 \mathrm{MHz}$ band, and TRACKER was run for 10 frequencies in this range. Figure 2 shows the pseudo-TEC data.

The agreement is surprisingly good-note that only one parameter, the sunspot number, was adjusted to

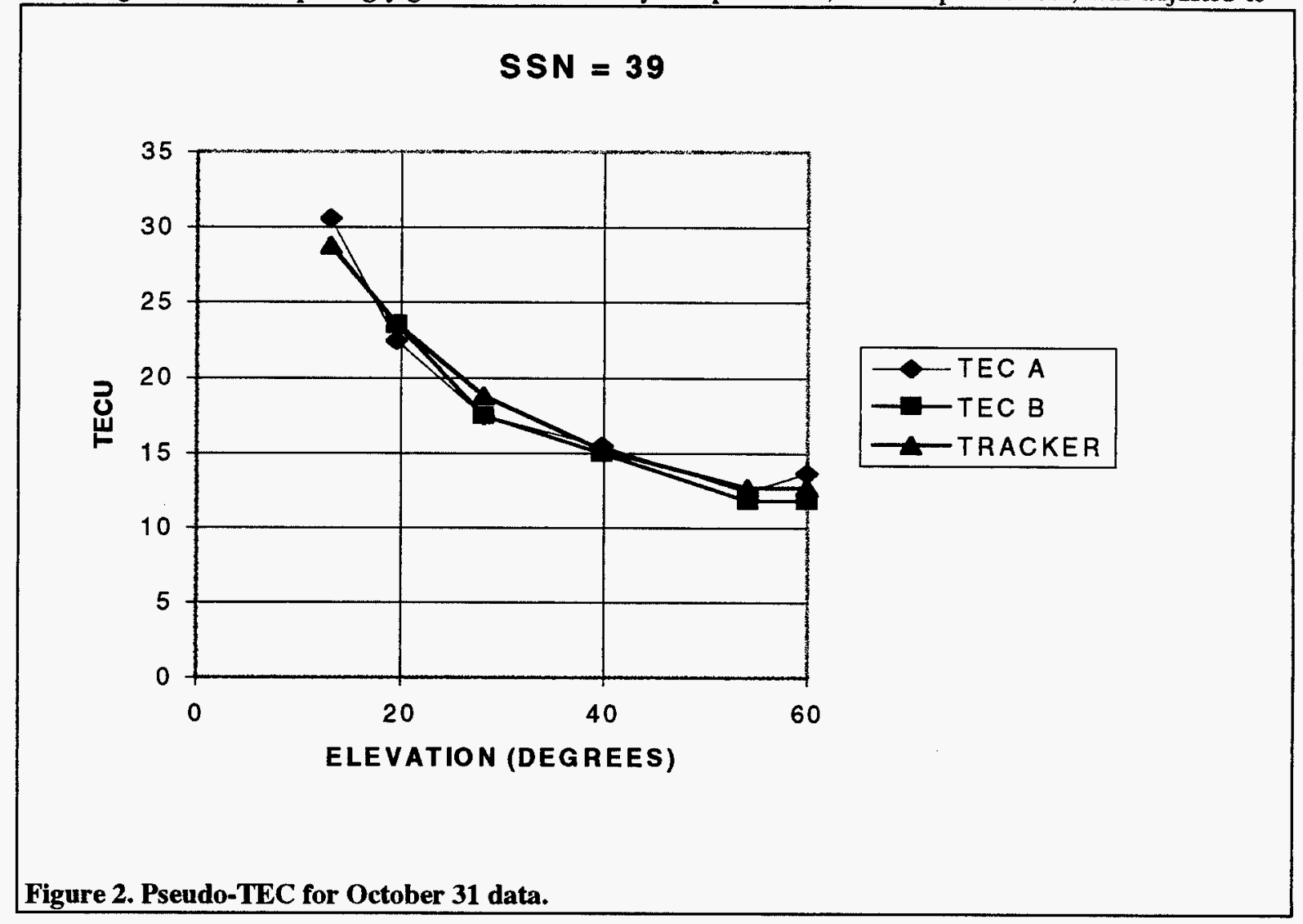

obtain this fit. 


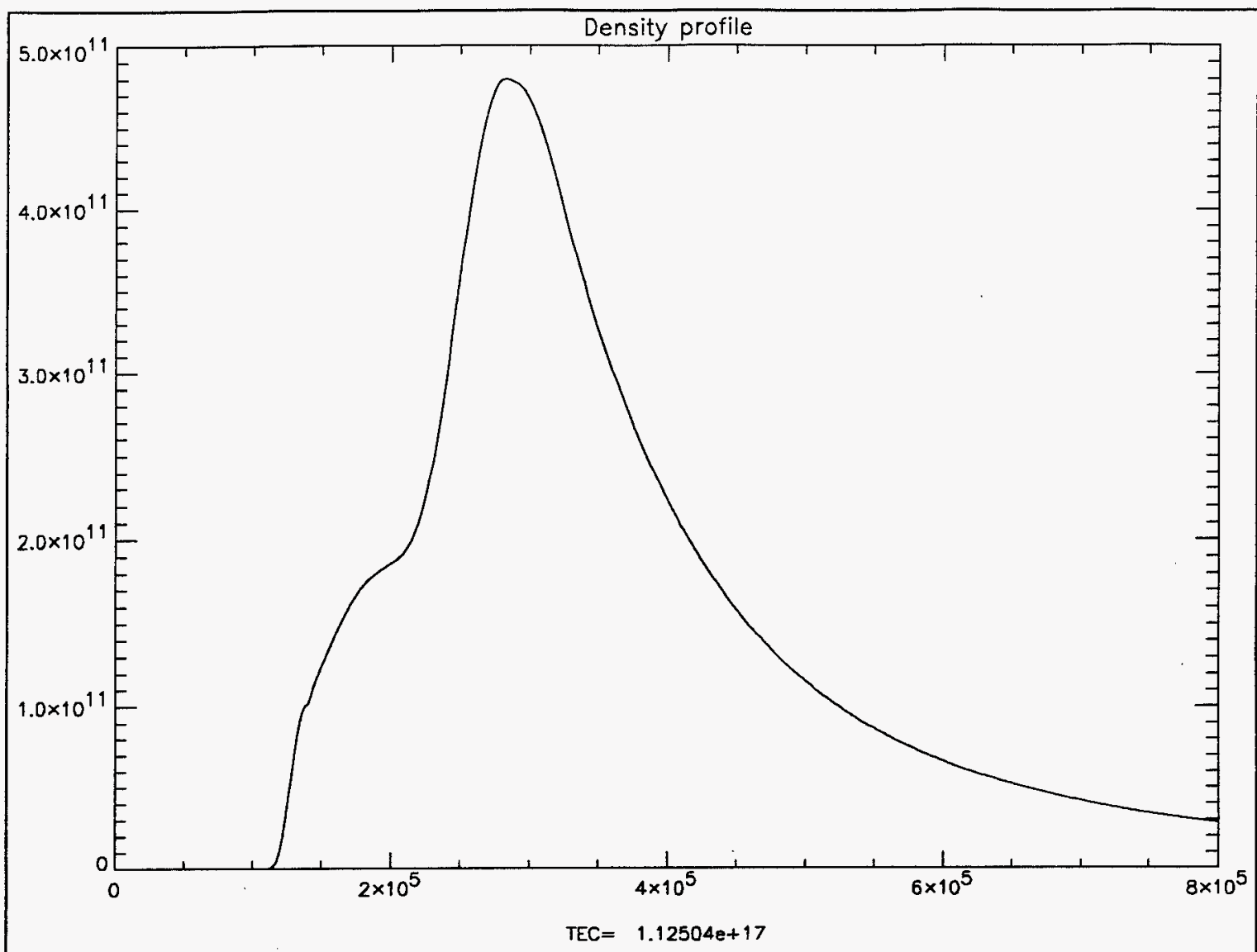

Figure 3. The computed electron density profile for the October 31 data. The line integral to $800 \mathrm{~km}$ is 11.2 TECU. The density is given in electrons $/ \mathrm{m}^{3}$, and the altitude is in meters.

The electron density profile over Los Alamos is shown in figure 3. Unfortunately, we do not have the TEC data from the JPL network for this date. The vertical TEC above Los Alamos to $800 \mathrm{~km}$, obtained by integrating the density profile, is 11.2 TECU.

\section{November 5 data.}

The data from November 5 are summarized in table 2 . The column headings the same as in the previous table. Both FORTE receivers were tuned to the $28-48 \mathrm{MHz}$ band, and the "coherent" analysis technique was used to estimate the pseudo-TECs.

\begin{tabular}{|r|r|r|r|r|r|r|r|r|}
\hline UT & AZ & EL & LAT & LON & ALT & TEC A & TEC B & TRACKER \\
\hline $23: 22: 00$ & 301.9 & 55.6 & 38.1 & -111.0 & 816452 & 14 & 14 & 14 \\
\hline $23: 23: 00$ & 248.6 & 67.3 & 34.9 & -109.4 & 816741 & 13 & 15 & 13 \\
\hline $23: 24: 00$ & 197.3 & 54.8 & 31.6 & -107.9 & 817084 & 16 & 16 & 14 \\
\hline $23: 25: 00$ & 181.2 & 38.6 & 28.3 & -106.5 & 817462 & 24 & 21 & 18 \\
\hline $23: 26: 00$ & 174.7 & 26.8 & 25.0 & -105.2 & 817904 & 28 & 26 & 23 \\
\hline $23: 27: 00$ & 171.3 & 18.5 & 21.7 & -104.0 & 818462 & 36 & 36 & 30 \\
\hline $23: 28: 00$ & 169.3 & 12.3 & 18.4 & -102.9 & 819149 & 45 & 47 & 38 \\
\hline
\end{tabular}

Table 2. Results from November 5 pass. 
The pseudo-TEC results are shown in figure 4.. The sunspot number used for this pass was 35 . The TRACKER model seems to underestimate the TEC (relative to the data) at lower elevation angles. The density profile above Los Alamos is shown in figure 5. Integration of that profile yields a true TEC above Los Alamos of 11.7 TECU to $800 \mathrm{~km}$. The GPS data from JPL estimated the TEC over Los Alamos to be 15.5 , implying that the TEC above $800 \mathrm{~km}$ was $3.8 \mathrm{TECU}$.
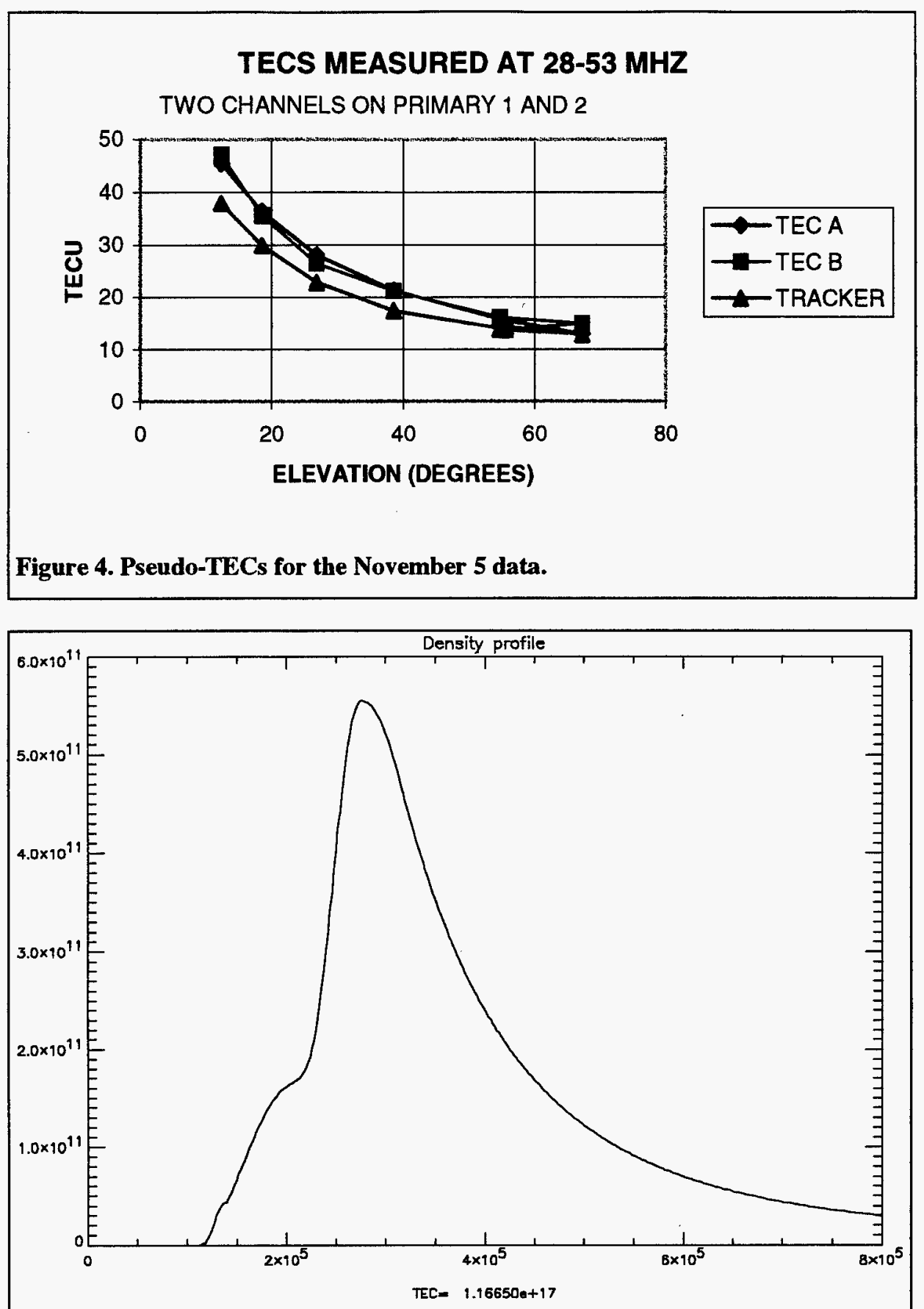

Figure 5. Electron density profile above Los Alamos for November 5. The vertical axis is electron density in electrons $/ \mathrm{m}^{3}$, and the altitude is in meters. 
November 18 data.

On this pass the TATR receivers were tuned to the 128-148 $\mathrm{Mhz}$ band and the $65-85 \mathrm{MHz}$ band. Dispersion within the higher band was too small to be measured reliably (at least until I have included better receiver calibration data than I have yet done), so the results shown here are from the $65-85 \mathrm{MHz}$ band, using the "incoherent" technique to obtain the pseudo-TEC. In order to fit the TRACKER result to the data at $67^{\circ}$ elevation, a sunspot number of zero had to be used, along with an ad hoc reduction in the entire density profile by a factor of 0.95 . As in the previous cases, these parameters were held fixed for the other shots.

The results are shown in table 3.

\begin{tabular}{|r|r|r|r|r|r|r|r|r|}
\hline UT & AZ & EL & RANGE & LAT & LON & ALT & TEC 75 & TRACKER \\
\hline $20: 12: 00$ & 107 & 67 & 901356.8 & 34.9 & 103.2 & 821 & 12.4 & 12.3 \\
\hline $20: 13: 00$ & 135 & 48 & 1102052 & 31.6 & 101.7 & 821 & 16.5 & 15.6 \\
\hline $20: 14: 00$ & 144 & 33 & 1396829 & 28.3 & 100.3 & 821 & 18.7 & 20.6 \\
\hline $20: 15: 00$ & 147 & 23 & 1737714 & 25.1 & 99 & 822 & 24.7 & 27.5 \\
\hline $20: 16: 00$ & 150 & 16 & 2101488 & 21.8 & 97.8 & 822 & 36.9 & 32.5 \\
\hline $20: 17: 00$ & 151 & 10 & 2477055 & 18.5 & 96.7 & 823 & 48.9 & 39 \\
\hline $20: 18: 00$ & 152 & 5 & 2789000 & 15.1 & 95.6 & 824 & 62.5 & 48 \\
\hline
\end{tabular}

Table 3. Results from November 18.

Figure 6 shows the TEC results. As in the November 5 data, the TRACKER results fall below the measurements at the lowest elevation angles, but agreement is fairly good above $15^{\circ}$. Figure 7 shows the density profile to $800 \mathrm{~km}$ over Los Alamos from the ionospheric model. The true vertical TEC to $800 \mathrm{~km}$ was 11.4 TECU. The GPS data from JPL estimated the TEC over Los Alamos to be 16.5 TECU, implying that the TEC above $800 \mathrm{~km}$ was 5.1 TECU.

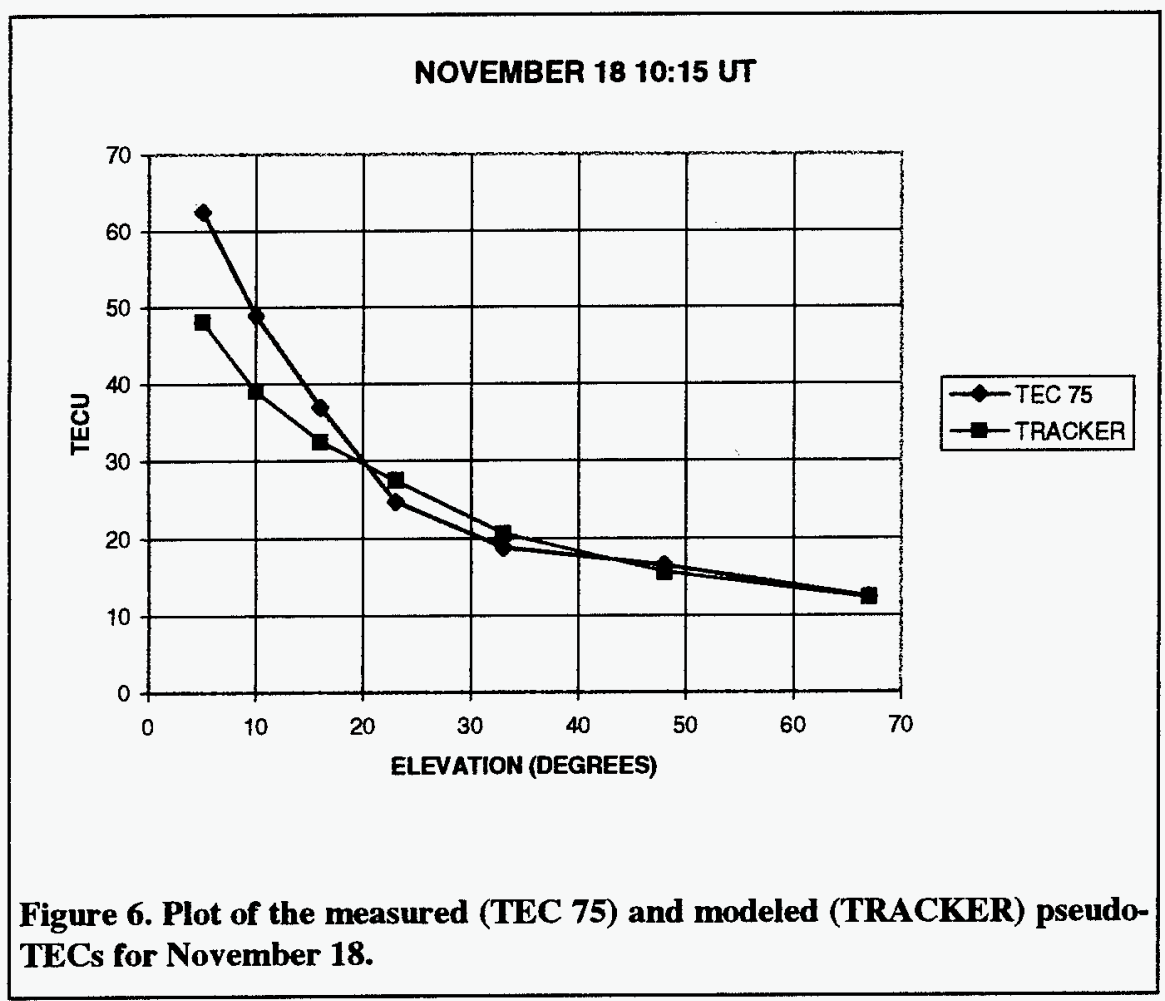




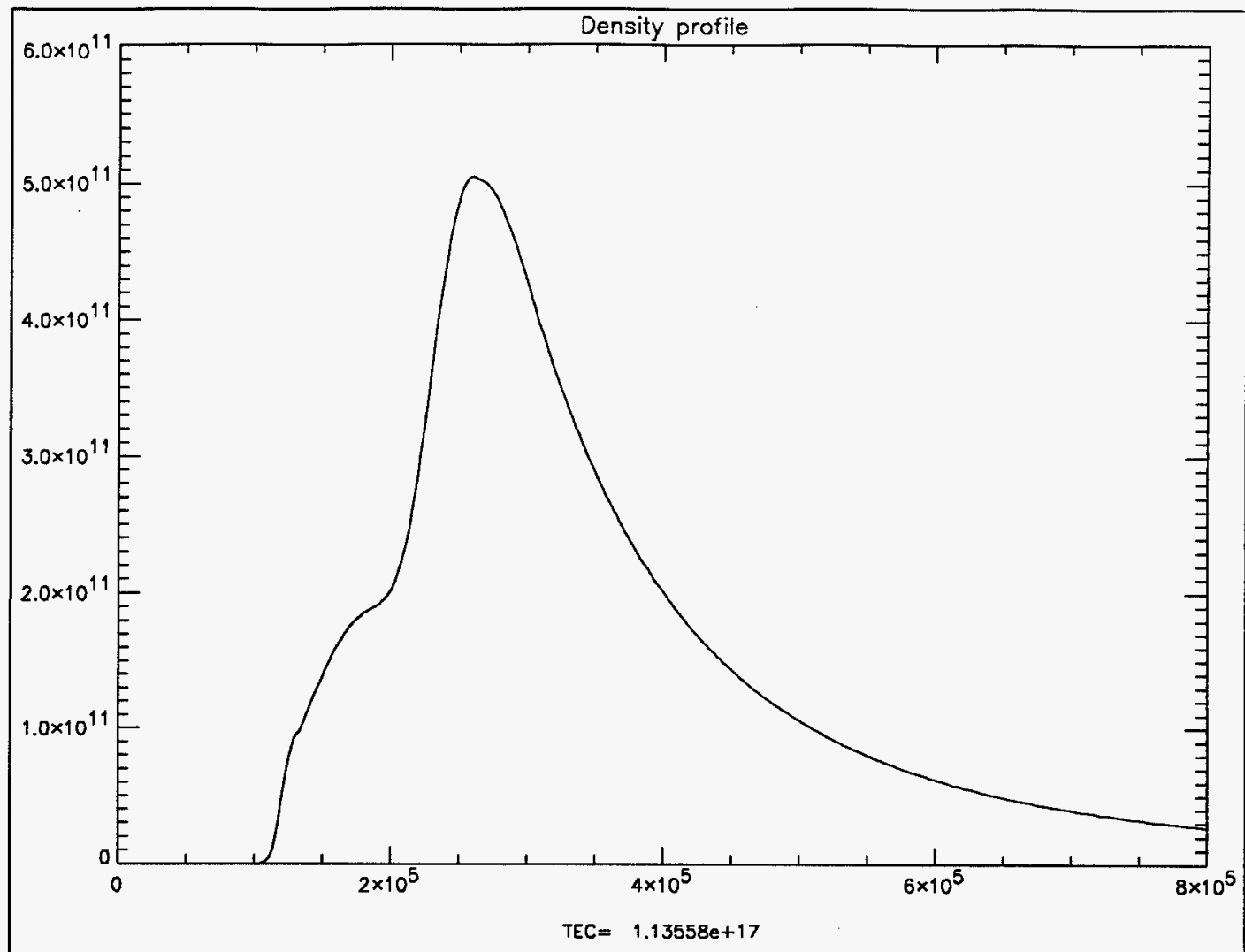

Figure 7. Plot of the modeled electron density $\left(\mathrm{m}^{-3}\right)$ versus altitude (m). The integral to 800 $\mathrm{km}$ is 11.4 TECU.

\section{Conclusions.}

The combination of FORTE data with the 3D ray-tracing code TRACKER appears to be a useful tool in obtaining vertical TEC. The absolute accuracy of the technique is difficult to assess, but the excellent agreement between the data and the model over elevation angles from $20-67^{\circ}$ implies that the errors are small enough to make these measurements quite useful. Comparison of these measurements with the measurements of TEC to the GPS orbit suggest that a substantial fraction of the TEC lies above $800 \mathrm{~km}$. Comparison of these and future results to upper-ionospheric and plasmaspheric models should prove fruitful. 


\section{M98004325}

||||||||||||||||||||||||||||||||||||||||||||||||||||||||||

Report Number (14) $L A-4 R--97-5 / 44$

Publ. Date (11)

199212

Sponsor Code (18) DOELDP, XF

UC Category (19) UC-700, DOE/ER 